\title{
Foetal instrumental extractions (IE) at the maternity at Nabil Choucair Health Center (Senegal) from 2005 to 2016: epidemio-clinical and prognostic aspects
}

\author{
Omar Gassama*, Ndeye Astou Faye, Abdoul Aziz Diouf, Mouhamadou Mansour Niang, \\ Magatte Mbaye, Daouda Ndour, Marie Edouard Faye Dieme, Ousmane Thiam, Abdou Ndiaye, \\ Alassane Diouf, Jean Charles Moreau
}

Obstetrics Clinic and Gynecology, Teaching Hospital, Aristide Le Dantec, Cheikh Anta Diop University, Dakar, Senegal

Received: 03 November 2017

Accepted: 22 December 2017

*Correspondence:

Dr. Omar Gassama,

E-mail: ogasse79@yahoo.fr

Copyright: (C) the author(s), publisher and licensee Medip Academy. This is an open-access article distributed under the terms of the Creative Commons Attribution Non-Commercial License, which permits unrestricted non-commercial use, distribution, and reproduction in any medium, provided the original work is properly cited.

\begin{abstract}
Background: The main objective was to take stock of practices on instrumental extractions at the maternity of Nabil Choucair Health Center.

Methods: This was a prospective, descriptive study from 1 January 2005 to 31 April 2016. The collection was carried out through the data sheet completed on the basis of an analysis of files, the delivery register and the anaesthesia register of the operating room. The data was entered using the Sphinx software version 5 and the data analysis performed by Epi info version 3.5 .

Results: 240 instrumental extraction cases were compiled, and their frequency was $0.4 \%$. The mean age of patients was 24.8 years. Obstetric vacuum was the most commonly used instrument $(66.4 \%)$ and an episiotomy was performed in $73.6 \%$. Maternal complications were dominated by simple perineal tears $(6.2 \%)$.

Conclusions: Instrumental extractions should be rehabilitated in our maternity facilities to combat the outbreak of the caesarean section. Instrumental extractions indications and techniques should be controlled to avoid complications.
\end{abstract}

Keywords: Forceps, Nabil Choucair health center, Obstetric vacuum, Spatula

\section{INTRODUCTION}

Instrumental extractions involve an assisted vaginal delivery using an instrument. Obstetricians have the choice between several foetal extraction instruments: forceps, obstetric vacuum and spatula. ${ }^{1}$ In recent years instrumental extractions have been relegated to the background in favor of cesarean section. The reasons given are the lack of adequate training for the handling of instruments, the unavailability of equipment for instrumental extractions.

The use of different instruments is variable in different regions of the world. Obstetric vacuum has for many years been widely used by the Northern Europe countries. Little use is made of spatulas in the world.

In Senegal, fetal instrumental extractions have been gradually declining. In Senegal, the forceps and the vacuum sucker are the two instruments most used for fetal instrumental extractions. Thierry's spatula is introduced as an instrument of fetal extraction in 2015 at the maternity ward of the Nabil Choucair health center in Dakar.

The technique, indications and conditions of application must be respected to avoid complications in the mother and the fetus. ${ }^{2}$ This study intends to take stock of instrumental 
extractions at the maternity of Nabil Choucair health center in Dakar (Senegal).

\section{METHODS}

This was a prospective, descriptive study on instrumental extractions from 1 January 2005 to 31 April 2016, i.e. a period of 136 months at the maternity of Nabil Choucair Health Center in Dakar. All deliveries by forceps or by obstetric vacuum or Thierry spatula were included.

Twin pregnancies, dystocic presentations such as siege, face presentation, and incomplete files were excluded from the study.

The collection was carried out through the data sheet completed on the basis of the delivery records analysis, the delivery register, the monthly reports and the anaesthesia register of the operating room.

The parameters studied concerned age, address, gynecological obstetric history, marital status, the results of the clinical examination at admission which assessed the constants, the general condition. Obstetrical examination data with the assessment of uterine height, fetal position, fetal heart sounds, presentation variability, membrane status, pelvic perfusion, and evolution of labor. Childbirth.

During the study we also specified the indications, the type of anesthesia, the type of instrument used, the type of presentation taken, the duration of the assisted delivery by an instrument, the fetal well being by the Apgar score at the fifth minute. We searched the maternal and fetal complications.

\section{Statistical analysis}

The data was entered using the Sphinx software version 5 and the data analysis performed using the Epi software version 3.5 .

\section{RESULTS}

\section{Frequency}

240 instrumental extractions were compiled on 55555 deliveries from 1 January 2005 to 31 April 2016, i.e. a period of 136 months at the maternity of Nabil Choucair health center in Dakar, a frequency of $0.4 \%$.

\section{Female patients' characteristics}

Age

The mean age of the patients was 24.8 years with extremes of 15 and 43 years. Patients belong mainly to the age groups of 19-24 and 25-34 years, or $40 \%$ and $41 \%$, respectively.
Table 1: Distribution of patients by gestity.

\begin{tabular}{|lll|}
\hline Gestity & Total number (n) & $\%$ \\
\hline Primigravidas & 130 & 54.2 \\
\hline Paucigravidas & 67 & 27.9 \\
\hline Multigravidas & 25 & 10.4 \\
\hline Major multigravidas & 18 & 7.5 \\
\hline Total & 240 & 100 \\
\hline
\end{tabular}

\section{Gestity and parity}

The mean gestity was 1.8 with limits of 1 to 10 gestity. The average parity was 1.6 with limits from 1 to 8 .

Table 2: Distribution of patients by parity.

\begin{tabular}{|lll|}
\hline Parity & n & $\%$ \\
\hline Primigravidas & 144 & 60 \\
\hline Paucigravidas & 67 & 27.9 \\
\hline Multigravidas & 13 & 5.4 \\
\hline Major multigravidas & 16 & 6.7 \\
\hline Total & 240 & 100 \\
\hline
\end{tabular}

\section{Parturient women's conditions for admission}

In our series, 170 patients $(69 \%)$ came of their own free will and 74 patients $(31 \%)$ were evacuated by other health facilities.

\section{Clinical examination at admission}

In the medical histories $15.8 \%$ of the parturient women had undergone a caesarean section and 1 patient $(0.4 \%)$ a myomectomy. In the prenatal follow-up, $88 \%$ of parturient women had made 3 prenatal visits.

\section{Table 3: Distribution of patients by variety of} position.

\begin{tabular}{|lll|}
\hline Position varieties & n & $\%$ \\
\hline ALOI* & 189 & 78.8 \\
\hline AROI* & 28 & 13.2 \\
\hline PROI* & 2 & 0.8 \\
\hline PLOI* & 2 & 0.8 \\
\hline Total & 240 & 100 \\
\hline
\end{tabular}

ALOI*: Anterior Left Occipito-Iliac, AROI*: Anterior Right Occipito-Iliac, PROI*: Posterior Right Occipito-Iliac, PLOI*: Posterior Left Occipito-Iliac

At admission the general condition was good in the majority of parturient women $(97 \%)$, the average gestational age was 39 Weeks of Amenorrhea (WA), the average fundal height was $33 \mathrm{~cm}$, the foetal heart tones were normal in $98 \%$ of parturient women. The vaginal examination revealed a dilated cervix like $5 \mathrm{~cm}$ on average, water breaking with a clear amniotic fluid in $98 \%$ of parturient women, a foetus in cephalic position in the anterior left occipital-iliac in $78.8 \%$ of cases, and pelvis was clinically normal in all parturient women (Table 3 ). 


\section{Labour data}

The majority of parturient women were admitted in the active phase of labour (80\%), compared with $48(20 \%)$ who had consulted at the beginning of labour.

This second phase of labour lasted an average of 3.9 hours with limits of 1 and 9 hours.

The duration of the push contraction phase was 37.6 minutes with limits of 12 to 120 minutes.

Labour monitoring by the correctly filled partogram was effective in 88 parturient women $(36.7 \%)$.

\section{Indications for instrumental extractions}

Indications were dominated by assisted expulsion due to maternal fatigue in $39.2 \%$ and obstructed labour in $36.2 \%$ and acute foetal distress in $15.4 \%$ as shown in Table 4 .

Table 4: Indications for instrumental extractions.

\begin{tabular}{|llc|}
\hline Indications & Total number (n) & $\%$ \\
\hline Maternal fatigue & 94 & 39.2 \\
\hline Obstructed labour & 87 & 36.2 \\
\hline Acute foetal distress & 37 & 15.4 \\
\hline Eclampsia & 10 & 4.2 \\
\hline Scarred uterus & 12 & 5 \\
\hline Total & 240 & 100 \\
\hline
\end{tabular}

\section{Surgical technic and instrument used}

Virtually all instrumental extractions were performed by medical doctors $(99.8 \%)$.

Instrumental extractions using obstetric vacuum were performed by midwives in 29 parturient women (1.2\%). During the instrumental extraction by application of forceps, 159 parturient women $(66.4 \%)$ had received a general anaesthesia with a mask.

Table 5: Instrument used during instrumental extractions.

\begin{tabular}{|lll|}
\hline Instrument used & Total number (n) & $\%$ \\
\hline Obstetric vacuum & 159 & 66.4 \\
\hline Forceps & 70 & 29.4 \\
\hline Spatula & 11 & 4.2 \\
\hline Total & 240 & 100 \\
\hline
\end{tabular}

Obstetric vacuum was the most widely used instrument $(66.4 \%)$ (Table 5).

Forceps foetal extraction was most often carried out directly in occipito-pubic position in $63(90 \%)$ parturient women. The grip was occipito-sacral and oblique in 5 parturient women (7\%) and 2 parturient women $(3 \%)$, respectively.

\section{Duration of instrumental extractions}

For the majority of parturient women (75\%), instrumental extraction was performed in less than 15 minutes (Table $6)$.

Table 6: Duration of interventions.

\begin{tabular}{|lll|}
\hline Duration of intervention & Total number (n) & $\%$ \\
\hline$\leq 15$ minutes & 180 & 75 \\
\hline $16-30$ minutes & 60 & 25 \\
\hline Total & 240 & 100 \\
\hline
\end{tabular}

\section{Neonatal parameters}

The mean birth weight was $2995 \mathrm{~g}$ with extremes of 2500 and 4000 and an Apgar score equal to 8 in $92 \%$ of newborns was noted.

\section{Prognostic aspects}

\section{Maternal}

In present study, maternal deaths were not recorded. However, perineal trauma such as episiotomies (73.6\%), perineal tears $(6.2 \%)$ and cervical tears $(1.2 \%)$ were noted.

\section{Neonatal}

After instrumental extractions, $13(82 \%)$ sero-sanguineous bumps were noted (Table 7).

Table 7: Neonatal complications during instrumental extractions.

\begin{tabular}{|lll|}
\hline & Effective (n) & $\%$ \\
\hline Sero-sanguineous bump & 13 & 82 \\
\hline Skin injuries & 1 & 6 \\
\hline Lesions of the face & 1 & 6 \\
\hline Nerve damage peripherals & 1 & 6 \\
\hline Total & 16 & 100 \\
\hline
\end{tabular}

\section{DISCUSSION}

\section{Socio-epidemiological characteristics}

Since the 1970s, instrumental extractions have declined significantly in the world. In Senegal, in Dakar at the Centre de Santé Nabil Choucair, the average rate is $0.43 \%$. Studies conducted under the same socio-economic conditions have also found a gradual decline over the years: $1.6 \%$ in 1996 and $1.38 \%$ in $2008 .^{3,4}$

We found an inversely proportional increase in the caesarean section rate from $12 \%$ of deliveries in 1992 to $17.5 \%$ in $1996 .{ }^{3}$

At the national level in a survey on Emergency Obstetric and Neonatal Care from 2012 to 2013, the national rate of 
caesarean section was $4.4 \%$ against $0.2 \%$ for instrumental extractions. $^{5}$

The majority of parturient women were primiparous women $(60 \%)$. In Senegal, studies carried out in the same socio-cultural context found $60.1 \%, 64.4 \%$ and $71.7 \%$ of primiparous women, respectively. ${ }^{4,6,7}$ In France, GERBERS had found $80 \%$ of primiparous women. ${ }^{8}$ This predominance of primiparous women is explained by a lack of knowledge of pushing efforts, maternal fatigue and systematic use of epidural anaesthesia during childbirth in developed countries. ${ }^{9}$

\section{Clinical aspects}

In our study, $97 \%$ of patients were carrying a foetus to full term. The same observation was made by several authors. . $^{3,7,10}$ The history of pelvic surgery was most often caesarean section (15.4\%). Indeed, CISSE in 1996 at the Obstetrics and Gynecological Clinics of Teaching hospitals Aristide Le Dantec had made the same observation. $^{3}$

\section{Indications, surgical technique, instrument type and duration of instrumental extractions}

In our series, the indications were dominated for maternal fatigue in $39.2 \%$ and for obstructed labour in $36.2 \%$ of cases.

Other authors had also found the predominance of maternal fatigue in instrumental extractions indications..$^{3,6,7}$ These are usually primiparous women with uncoordinated and ineffective pushing efforts and lack of cooperation due to the lack of preparation for childbirth in our societies. In addition, the use of instrumental extractions for coma during eclampsia crises (4.2\%) can be added.

The acute foetal distress as the third indication in our series is analogous to the results of several authors..$^{3,4}$ The recommendations for clinical practice of the French National College of Gynaecologists Obstetricians mention acute foetal distress as the main indication of instrumental extractions. $^{9}$

The difference in indications is explained by the early and sometimes "abusive" diagnosis of acute foetal distress in developed countries through labour monitoring such as foetal heartbeat recording, foetal blood $\mathrm{pH}$ after scalp micropuncture. On the other hand, in our context, clinical means such as listening for the baby's heartbeat through the Pinard stethoscope and the changes in colour of the amniotic fluid.

In present study, 5\% of the patients underwent an instrumental extraction for scarred uterus. Present results

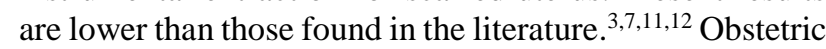
vacuum was the most used instrument (66.4\%) in deliveries compared with $29.4 \%$ for forceps and $4.2 \%$ for spatula.

In recent years, the use of vacuum has increased significantly at the expense of forceps in France and Anglo-Saxon countries. ${ }^{13}$ In Senegal, forceps and vacuum are the two main instruments used. ${ }^{5,6}$ Publications in the United States have shown in some areas a majority use of vacuum. ${ }^{12,14,15}$

Spatula as an instrument of instrumental extraction was introduced in 2015 to the maternity at Nabil Choucair health center, which explains the still low rate (4.2\%).

This instrument is used exclusively in France. It is used as a first-line instrument in some areas and seems less difficult to handle than forceps.

\section{Prognostic aspects}

\section{Maternal}

In our series, $73.6 \%$ of parturient women received an episiotomy. This frequency is lower than that found by several authors $(92.2 \%)$ or Menard et al $(80.2 \%){ }^{4,15,16}$ Indeed, the systematic practice of episiotomy during instrumental extractions is a controversial issue. The publication of the article by Leeuw et al called into question the recommendations for clinical practice of the CNGOF of 2006 that episiotomy during an instrumental extraction should not be used liberally but should be left to the practitioner's clinical common sense to guide the recourse or not to this perineotomy. ${ }^{9,15}$ Indeed, this important study of the Dutch Register on nearly 33000 instrumental extractions concluded that episiotomy reduces the risk of anal sphincter tears in case of instrumental extractions.

Cervical tears are rarely involved in the occurrence of postpartum haemorrhage during instrumental extractions. ${ }^{9}$

\section{Neonatal}

In present study, 92\% of new-borns had an Apgar score greater than 8 in the fifth minute. This good Apgar score proves that instrumental extraction is not very traumatic if indications are well established, conditions of application adhered to and technique mastered. , $^{3,4,7,10}$

In present series, foetal morbidity was dominated by the sero-sanguineous hump, which is a minor lesion often not specific to instrumental extractions. ${ }^{10}$ Claris reports that the indication opportunity and operator's skill greatly influence the neonatal prognosis. ${ }^{17}$

\section{CONCLUSION}

Instrumental extractions should be rehabilitated in our maternity facilities to combat the outbreak of caesarean sections. Instructions and techniques for instrumental 
extractions should be mastered to avoid complications. Spatulas should also be part of the arsenal of instruments for instrumental extractions in our maternity facilities.

Funding: No funding sources

Conflict of interest: None declared

Ethical approval: Not required

\section{REFERENCES}

1. Mangin M, Ramanah, Aouar Z, Courtois L, Collin A. Data 2007 of instrumental extraction in France: results of a national survey of all university hospital centers. J Gynecol Obstet Biol Reprod. 2010;28:121-32.

2. Bergsjo P. Differences in the reported frequencies of some obstetrical interventions in Europe Br J Obstet Gynaecol. 1983;90:628-32.

3. Cisse CT, Ewaginon E, Fotso A, Maitournam F, Moreau JC, Diadhiou F. Indications and prognosis of forceps delivery at the CHU de Dakar. Dakar Med. 1998;43(2):220-4.

4. Diouf AB. Epidemiology and prognosis of instrumental extractions in maternity of the Institute of Social Hygiene of Dakar. Memorial Med. 2010(258).

5. MSAS UNFPA- OMS- UNICEF- CEFOREP. Assessment of Care Needs Obstetric and Neonatal Urgency in Senegal 2012-2013 Report, Dakar, December 2014:179.

6. Ndao D. Forceps delivery in Senegal: results three surveys on the obstetric-surgical coverage of the country. Thesis Med. 2007;3:112.

7. Sow DB. Prognosis of obstetric vacuum delivery at the Center National Hospital of Pikine. Thesis Med. 2013(99)

8. Gerbers VY, Hohlfeld P. Maternal and neonatal prognosis in a second prolonged delivery phase. $\mathrm{J}$ Gynecol Obstet Biol Reprod. 1999;28(2):145-50.

9. National College of French Obstetrician Gynecologists. Text of recommendations.
Instrumental extractions. Midwife Magazine. 2009;8:104-7.

10. Boni S, Abauleth R, Gondo D, Koffi A, Effoh D, Kone N. Indications of instrumental extractions and foeto-maternal prognosis at Cocody CHU. J de la Sago. 2005;6(1):1-5.

11. Thoulon JM, Castro MA, Lieux JM, Magin P. Applications of forceps in a university hospital. Review. French Gynecol Obstet. 1974;69:487-97.

12. Towner D, Castro MA, Eby-Wilkens E, Gilbert WM. Effect of mode of delivery in nulliparous woman on neonatal intra cranial injury. $N$ Engl $J$ Med. 1999;341:1709-14.

13. Oury JF. Instrumental extractions. J Gynecol Obstet Biol Reprod. 2008;37:S175-S176.

14. Learman LA. Regional differences in operative obstetrics: a look to the south. Obstet Gynecol. 1998;92:514-9.

15. De Leeuw JW, De Wit C, Kuijken JP, Bruinse HW. Mediolateral episiotomy reduces the risk for anal sphincter injury during operative vaginal delivery. BJOG. 2008;115:104-8.

16. Menard J, Provansal M, Heckenroth H, Gamere M, Bretelle F, Manzouni C. Immediate maternal morbidity after instrumental extraction by Thierry's spatula and by vacuum suction cup. Gynecol Obstet Fertil. 2008;36:623-7.

17. Claris O. The risks of forceps: the point of view of the pediatrician and the obstetrician. Review. French Gynecol Obstetric. 1990; 85(10):549-51.

Cite this article as: Gassama O, Faye NA, Diouf AA, Niang MM, Mbaye M, Ndour D et al. Foetal instrumental extractions (IE) at the maternity at Nabil Choucair Health Center (Senegal) from 2005 to 2016: epidemio-clinical and prognostic aspects. Int J Reprod Contracept Obstet Gynecol 2018;7:386-90. 